\title{
Mortality and type of cigarette smoked
}

\author{
P. N. LEE \\ Independent Consultant in Statistics and Adviser in Epidemiology, Sutton \\ L. GARFINKEL \\ From the American Cancer Society, New York
}

SUMmARY Twenty-five years ago, cigarette smokers in the United Kingdom smoked plain cigarettes with an average tar yield of probably about $35 \mathrm{mg}$. Now smokers predominantly smoke filter cigarettes and average tar yields have been reduced by half. Epidemiological evidence comparing mortality in smokers of differing types of cigarettes is reviewed. Compared with smokers of higher tar plain cigarettes, smokers of lower tar filter cigarettes have a reduced mortality for lung cancer, for cancer of the buccal cavity, pharynx, larynx, oesophagus, and bladder, for chronic bronchitis and emphysema, and for cirrhosis of the liver. They also have a slightly reduced mortality for coronary heart disease and stroke. Not all these differences are statistically significant. Problems of interpretation and limitations of the available evidence are discussed. No worthwhile evidence is yet available on smokers of 'low tar' (0-10 mg) cigarettes and data are sparse on lifetime smokers of filter cigarettes. Continuing research is important to understand the situation fully, but the trends for lower mortality to be associated with lower tar and nicotine levels are promising.

The association between cigarette smoking and carcinoma of the lung was first clearly demonstrated by Doll and Hill in $1950 .{ }^{1}$ Since then, evidence has accumulated and cigarette smoking has now been associated with mortality from coronary heart disease, chronic bronchitis, cancers of other sites, and a number of other diseases. ${ }^{2} 3$

Since 1950, there have been marked changes in the type of cigarette commonly smoked in many Western countries. In the United Kingdom, in 1955, virtually all smokers smoked plain cigarettes which probably had tar yields of about $35 \mathrm{mg}$ a cigarette.4 Ten years later half of the smokers were using cigarettes which had filters, but filters which were inefficient and reduced tar yields only slightly. Subsequently, the use of filters increased and filter efficiency improved, so that by 1975 the majority of smokers smoked cigarettes with tar yields about half that of the average old plain cigarette (Table 1). In recent years, a third change has started to occur, with over $10 \%$ of smokers now smoking cigarettes with a tar yield of 10 mg or less. This trend, high $\operatorname{tar}^{*}$ plain $\rightarrow$ high tar filter

*Unless otherwise stated, we use the tar grouping as defined for United Kingdom Department of Health and Social Security league tables: high $(29 \mathrm{mg}+)$, middle to high (23-28 mg), middle (17-22 mg), low to middle (11-16 mg), and low (0-10 mg).
Table 1 Changes in type of cigarette sold, UK, 1955-77

\begin{tabular}{cccclllll}
\hline & \multicolumn{3}{l}{ Market share (\%) } & & \multicolumn{3}{l}{ Mean tar (mg/cig) } \\
\cline { 2 - 3 } \cline { 6 - 8 } Year & Plain & Filter & 'Low tar' & & Plain & Filter & All brands \\
\hline 1955 & 98.1 & 1.9 & - & & No data & No data & No data \\
1960 & 84.2 & 15.8 & - & & No data & No data & No data \\
1965 & 47.0 & 53.0 & - & & 35.0 & 29.3 & 31.4 \\
1970 & 21.7 & 78.3 & - & & 29.6 & 20.6 & 22.5 \\
1972 & 18.3 & 81.7 & - & & 27.8 & 18.9 & 20.5 \\
1975 & 13.4 & 86.6 & 4.8 & & 24.8 & 16.9 & 17.9 \\
1977 & 10.0 & 90.0 & 12.4 & & 24.7 & 16.5 & 17.3
\end{tabular}

Data from Leess and supplements; data for low tar (0-10 mg/cig) market share from Tar Data Aggregation Scheme.

$\rightarrow$ middle tar filter $\rightarrow$ low tar filter, has been repeated in a number of other countries but with differing time scales. Evidence summarised by Weber ${ }^{5}$ shows that these changes have tended to occur earlier in the United States of America, Germany, and Switzerland, than in the United Kingdom and later in France.

A general reduction in the average nicotine yield of cigarettes smoked has been associated with these tar reductions, since tar and nicotine yields of brands are generally quite closely correlated. Direct evidence on long-term trends in carbon monoxide yields is not available but it is probable, at least in the United Kingdom, that an increasing use of high porosity 
paper in cigarettes has led to current cigarettes having rather lower $\mathrm{CO}$ yields than older cigarettes. Until recently, high porosity paper has been used more in plain cigarettes than in filter cigarettes, which may explain why Wald ${ }^{8}$ observed higher average $\mathrm{CO}$ yields in a sample of United Kingdom filter cigarettes than in a sample of plain cigarettes.

In view of the association between mortality and cigarette smoking, it is of obvious importance to know whether this association is weaker for the more modern types of cigarette than for the old high tar plain cigarette. It is the object of this paper to review the evidence and to present some new data from the American Cancer Society's prospective study and from the British samples of the study of migrants in Great Britain, Norway, and the USA.

\section{EPIDEMIOLOGICAL DATA AVAILABLE}

Relevant epidemiological studies for which results are available are summarised in Table 2 (prospective) and Table 3 (retrospective). With two exceptions, the relatively small hospital study of $\mathrm{Koch}^{7}$ and the case-control study by Kunze, ${ }^{8}$ all the studies listed are based on American or United Kingdom samples. The majority of the studies compare smokers of plain ánd filter cigarettes; but the American Cancer Society study of Hammond $e t$ $a l^{9}$ compared smokers by tar and nicotine level of brand smoked. For the first six-year period of the study (1960-66), 'high $\mathrm{T} / \mathrm{N}$ ' was defined as more than $2.0 \mathrm{mg}$ nicotine and $25.8 \mathrm{mg} \operatorname{tar}$, 'low $\mathrm{T} / \mathrm{N}$ ' as less than $1.2 \mathrm{mg}$ nicotine and less than $17.6 \mathrm{mg}$ tar, and 'medium $\mathrm{T} / \mathrm{N}$ ' as intermediate. For the second six years of this study (1966-72), the definition of low $\mathrm{T} / \mathrm{N}$ was the same but the high $\mathrm{T} / \mathrm{N}$ category had to be lowered somewhat because of changes in the product over the previous six years.

One pathological study is also of relevance to this review. Auerbach et al ${ }^{10}$ compared histological changes in the bronchial epithelium of 211 men dying and coming to necropsy in New Jersey in 1955-60 with those of 234 similar men dying in 1970-77.

In Tables $4,5,6,7$, and 8 the mortality ratios take the mortality of smokers of plain cigarettes as the denominator. In the American Cancer Society data, the denominators are smokers of brands of cigarettes with relatively high tar and nicotine $(T / N)$. Numbers of deaths shown in the Tables are the combined numbers of deaths in the two groups of smokers being compared; deaths in the American Cancer Society

Table 2 Prospective epidemiological studies relating mortality to type of cigarette smoked

\begin{tabular}{|c|c|c|c|c|c|c|}
\hline Study (refs) & Sample & $\begin{array}{l}\text { INITIALL } \\
\text { Date }\end{array}$ & $\begin{array}{l}\text { STIONNAIRE } \\
\text { Sample size }\end{array}$ & $\begin{array}{l}\text { FOLLOW-UP } \\
\text { Period }\end{array}$ & Reinterviews & No of deaths \\
\hline $\begin{array}{l}\text { American Cancer Society: } \\
\text { Hammond }\end{array}$ & $\begin{array}{l}\text { Subjects in } 25 \text { States of } \\
\text { America }\end{array}$ & $1959-60$ & Over 1000000 & 12 years & $\begin{array}{l}\text { Annual follow-up } \\
\text { and requestioning } \\
\text { four times. }\end{array}$ & $\begin{array}{l}\text { 'Adjusted' no. of } \\
13027 \text { deaths analysed }\end{array}$ \\
\hline Hawthorne's & $\begin{array}{l}\text { 45-64-year-olds } \\
\text { attending multiphasic } \\
\text { screening in Scotland }\end{array}$ & $1968-75$ & 18786 & Until 1977 & None & 925 \\
\hline Migrants ${ }^{17}$ & $\begin{array}{l}\text { British population: } \\
\text { random sample plus } \\
\text { sample of siblings of } \\
\text { UK migrants to USA }\end{array}$ & $1964-65$ & 17696 & Until 1977 & None & 3170 \\
\hline
\end{tabular}

Table 3 Retrospective epidemiological studies relating mortality to type of cigarette smoked

\begin{tabular}{|c|c|c|c|c|}
\hline Study (refs) & Sample and type of study & Diseases studied & $\begin{array}{l}\text { No. of } \\
\text { cases }\end{array}$ & $\begin{array}{l}\text { No. of } \\
\text { controls }\end{array}$ \\
\hline Doll and Hillº & Hospital matched case-control study: England 1948-52 & Lung cancer & 1465 & 1465 \\
\hline Dean'e & $\begin{array}{l}\text { Case data referable to decedents in north-east } \\
\text { England } 1966-72 \text { obtained from relatives; } \\
\text { control data from living population in same area }\end{array}$ & $\begin{array}{l}\text { Lung cancer, coronary heart } \\
\text { disease, chronic bronchitis } \\
\text { and stroke }\end{array}$ & 2370 & 5521 \\
\hline Bross and Gibson ${ }^{11}$ & Hospital matched case-control study: USA $1960-66$ & Lung cancer & 974 & 974 \\
\hline Koch? & Hospital case-control study: Germany 1974 & $\begin{array}{l}\text { Peripheral arterial } \\
\text { occlusive disease }\end{array}$ & 236 & 154 \\
\hline Wynder 1213 i4 & $\begin{array}{l}\text { Two hospital matched case-control studies: } \\
\text { USA } 1966 \text { onwards }\end{array}$ & $\begin{array}{l}\text { Lung cancer, larynx } \\
\text { cancer and peripheral } \\
\text { vascular disease }\end{array}$ & & \\
\hline Kunze• & Hospital case-control study: Austria 1976-79 & Lung cancer & 684 & 1156 \\
\hline
\end{tabular}


Table 4 Relative all-causes mortality by type of cigarette smoked

\begin{tabular}{|c|c|c|c|c|c|c|c|}
\hline \multirow[b]{2}{*}{ Study (refs) } & \multirow[b]{2}{*}{ Comparison } & \multicolumn{3}{|l|}{$M E N$} & \multicolumn{3}{|c|}{ WOMEN } \\
\hline & & Deaths* & $\begin{array}{l}\text { Relative } \\
\text { mortality }\end{array}$ & $p$ & Deaths* & $\begin{array}{l}\text { Relative } \\
\text { mortality }\end{array}$ & $p$ \\
\hline Hammond $1960-66$ & $\begin{array}{l}\text { Low } v \text { high } T / N \\
\text { Med } v \text { high } T / N\end{array}$ & $\begin{array}{r}3021 \\
10083\end{array}$ & $\begin{array}{l}0.89 \\
0.91\end{array}$ & $\begin{array}{l}<0.00001 \\
<0.00001\end{array}$ & $\begin{array}{l}2338 \\
3266\end{array}$ & $\begin{array}{l}0.84 \\
0.89\end{array}$ & $\begin{array}{l}<0.00001 \\
<0.001\end{array}$ \\
\hline Hammond $1966-72$ & $\begin{array}{l}\text { Low } v \text { high } T / N \\
\text { Med } v \text { high } T / N\end{array}$ & $\begin{array}{ll}1 & 774 \\
8 & 153\end{array}$ & $\begin{array}{l}0.82 \\
0.97\end{array}$ & $\begin{array}{l}<0.00001 \\
\text { NS }\end{array}$ & $\begin{array}{l}1845 \\
2721\end{array}$ & $\begin{array}{l}0.83 \\
0.87\end{array}$ & $\begin{array}{l}<0.00001 \\
<0.00001\end{array}$ \\
\hline Hawthorne ${ }^{15}$ & Filter $v$ plain & 507 & 1.02 & NS & - & - & - \\
\hline Migrants $^{17}$ & Filter $\mathbf{v}$ plain & 650 & 0.90 & NS & 292 & 0.83 & NS \\
\hline
\end{tabular}

*Deaths in Hammond study are 'adjusted' deaths.

Table 5 Relative lung cancer mortality by type of cigarette smoked

\begin{tabular}{|c|c|c|c|c|c|c|c|}
\hline \multirow[b]{2}{*}{ Study (refs) } & \multirow[b]{2}{*}{ Comparison } & \multicolumn{3}{|l|}{$M E N$} & \multicolumn{3}{|c|}{ WOMEN } \\
\hline & & $\begin{array}{l}\text { Deaths/ } \\
\text { cases }\end{array}$ & $\begin{array}{l}\text { Relative } \\
\text { mortality }\end{array}$ & $p$ & $\begin{array}{l}\text { Deaths/ } \\
\text { cases }\end{array}$ & $\begin{array}{l}\text { Relative } \\
\text { mortality }\end{array}$ & $p$ \\
\hline $\begin{array}{l}\text { (a) Prospective } \\
\text { Hammond } 1960-66\end{array}$ & $\begin{array}{l}\text { Low v high T/N } \\
\text { Med v high T/N }\end{array}$ & $\begin{array}{l}229 \\
843\end{array}$ & $\begin{array}{l}0.82 \\
0.95\end{array}$ & $\begin{array}{l}\text { NS } \\
\text { NS }\end{array}$ & $\begin{array}{r}76 \\
119\end{array}$ & $\begin{array}{l}0.57 \\
0.88\end{array}$ & $\begin{array}{l}<0 \cdot 02 \\
\text { NS }\end{array}$ \\
\hline Hammond $1966-72$ & $\begin{array}{l}\text { Low v high } T / N \\
\text { Med v high } T / N\end{array}$ & $\begin{array}{l}162 \\
784\end{array}$ & $\begin{array}{l}0.80 \\
0.94\end{array}$ & $\begin{array}{l}\text { NS } \\
\text { NS }\end{array}$ & $\begin{array}{r}94 \\
150\end{array}$ & $\begin{array}{l}0.63 \\
0.74\end{array}$ & $\begin{array}{r}<0.02 \\
0.05\end{array}$ \\
\hline Hawthorne ${ }^{15}$ & Filter $v$ plain & 80 & 0.84 & NS & - & - & - \\
\hline Migrants $^{17}$ & Filter v plain & 99 & $1 \cdot 12$ & NS & 21 & 0.98 & NS \\
\hline $\begin{array}{l}\text { (b) Retrospective } \\
\text { Dean' }\end{array}$ & Filter v plain & 332 & 0.54 & $<0.001$ & 101 & 0.68 & NS \\
\hline Wynder $^{12} 1970$ & Filter $v$ plain & 157 & 0.55 & $<0.01$ & - & - & - \\
\hline Wynder $^{14} 1979$ & Filter $\mathbf{v}$ plain & 293 & 0.76 & $<0.05$ & 63 & 0.75 & NS \\
\hline
\end{tabular}

Table 6 Relative mortality for various sites of cancer by type of cigarette smoked: American Cancer Society Study

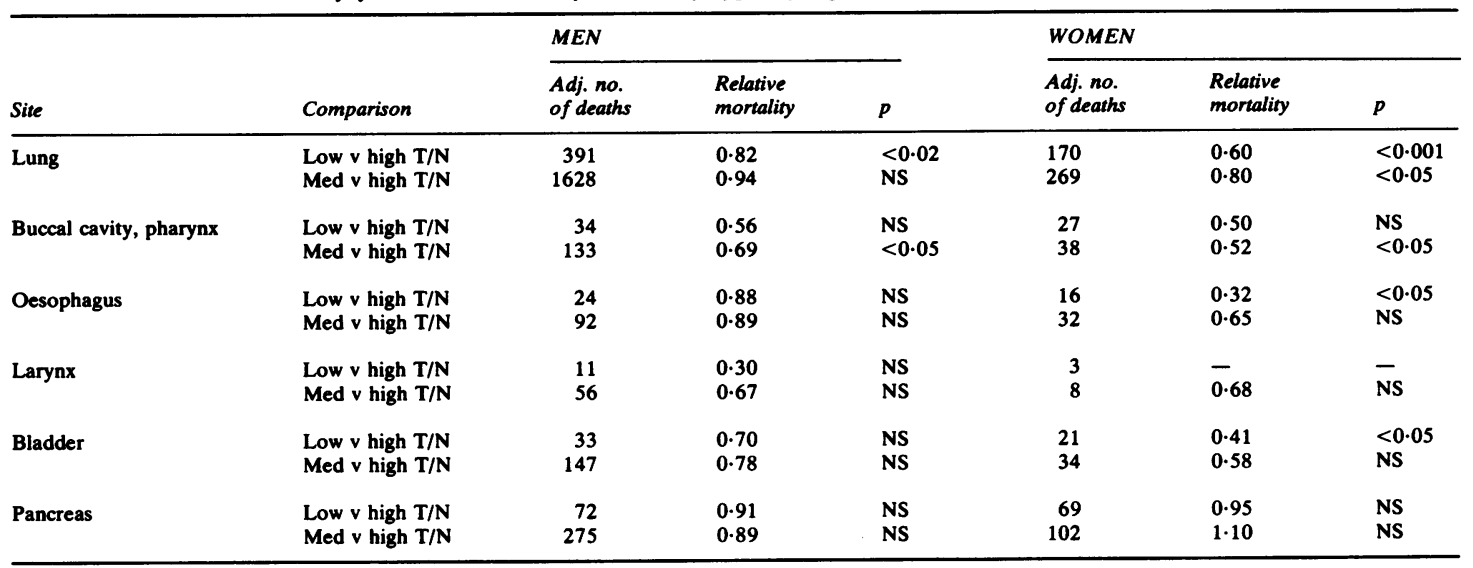


Table 7 Relative coronary heart disease mortality by type of cigarette smoked

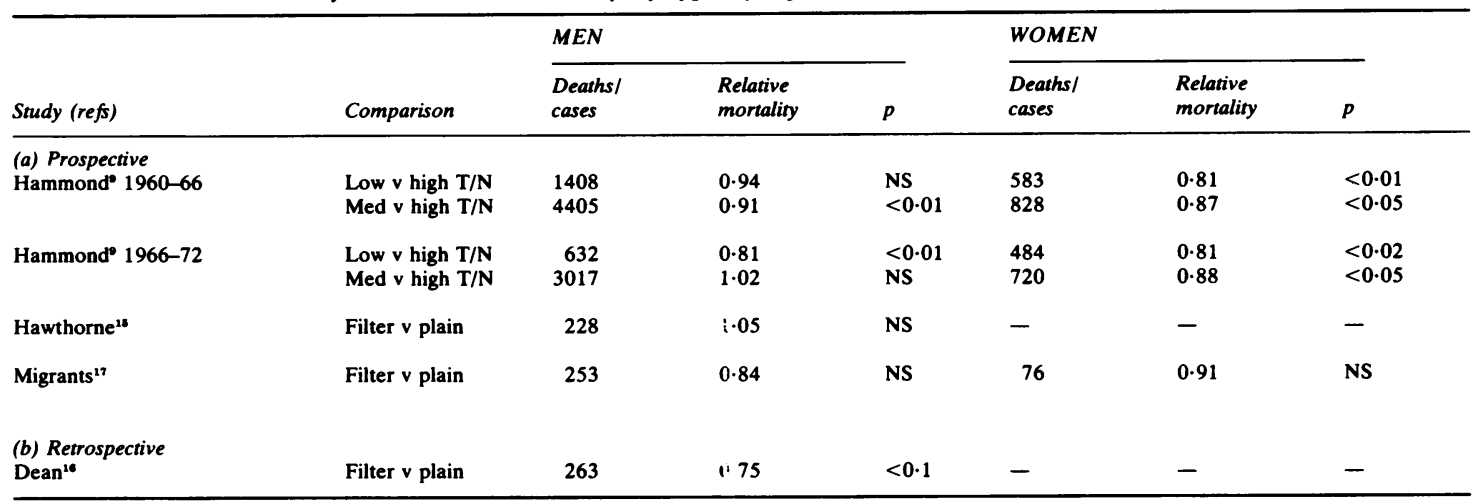

Table 8 Relative mortality for other sites associated with smoking by type of cigarette smoked: American Cancer Society Study

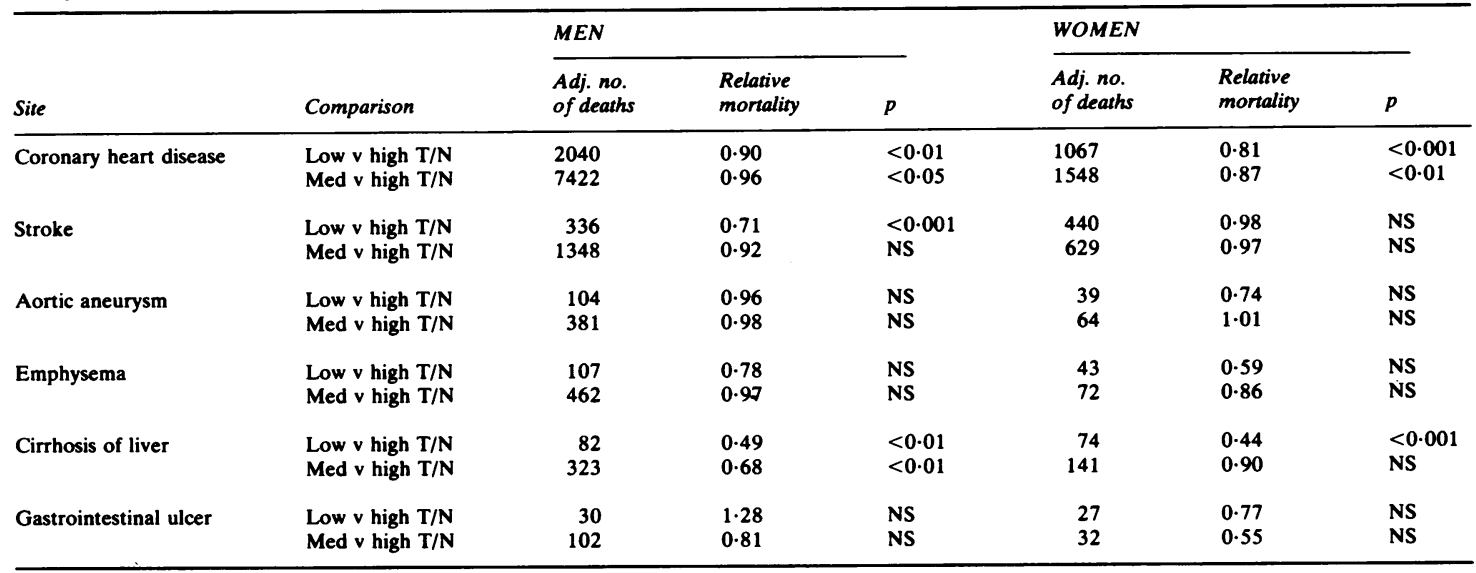

study are 'adjusted deaths' as defined by Hammond. ${ }^{9}$ In this study, variances were computed for each of the individual matched groups and summed over all groups. The summed variances were used to compute probability levels for differences in adjusted numbers of deaths for high vs. medium $\mathrm{T} / \mathrm{N}$ and high vs. low $\mathrm{T} / \mathrm{N}$ smokers. In all studies comparisons not statistically significant (NS) are defined as $p>0.05$.

Mortality ratios in the Hammond study are based on analyses matching for age, race, number of cigarettes a day, age of starting to smoke, place of residence, occupational exposure to five variables, education and history of lung cancer or heart disease. For the coronary heart disease analysis, nine additional relevant variables were matched. Those in the Bross and Gibson ${ }^{11}$ and Wynder ${ }^{12} 1314$ studies are matched for age and hospital admission date; those in the Hawthorne ${ }^{15}$ and Dean ${ }^{16}$ studies are standardised for age and number smoked, and those in the migrants study ${ }^{17}$ for age, number smoked, inhalation, and age of starting. In Wynder's studies, filter implies filter cigarettes smoked for at least 10 years.

Before examining the evidence from these epidemiological and pathological studies, it is worth looking briefly at the limitations of such data and the problems of interpreting them.

LIMITATIONS AND PROBLEMS OF IN TER PRETATION

(1) None of the studies carried out give any useful information on lifetime smoking of any type of cigarette other than the old plain variety, and even for these brands, the $T / N$ has been drastically reduced over the years. Similarly, those people studied who claim always to have smoked filter cigarettes are likely to have reduced their tar yield, because virtually all filter cigarettes have had reduced tar yields over the last 15-20 years. The 
association between lung cancer and age of starting to smoke $^{18}{ }^{10}$ suggests that smoking early in life may be of importance, and, therefore, that without studies of lifetime smoking of one type of cigarette which did not vary in $T / N$ yield, the magnitude of the association cannot be fully established.

(2) None of the studies give any information on low tar cigarettes as defined above. The studies summarised here are, at best, comparisons of smokers who have continued to use high tar plain cigarettes (and even these have changed over time) with those who have switched to what we now classify as low to middle or middle tar filter cigarettes.

(3) Particular types of study designs are likely to impart bias in different ways. Prospective studies may be biased because some smokers observed to be plain cigarette smokers when interviewed will actually have switched to filter cigarettes before the end of the follow-up period, and retrospective studies, especially where information is obtained second-hand from relatives, are subject to memory bias.

(4) Smokers of plain cigarettes tend to be older and of lower social class, to be worse educated, to have less skilled jobs with more industrial exposure, to drink beer relatively more often, and coffee, spirits, and wine relatively less often, than those who smoke filter cigarettes. ${ }^{18}{ }^{20}$ They also tend to smoke more cigarettes, to inhale more deeply, and to have started smoking earlier. ${ }^{21}$ One statistical method of dealing with such complications is to standardise for the variables that differ. But, from a public health point of view, a reduced health association for each cigarette is not much use if the typical smoker, on switching to filters, smokes more cigarettes and inhales them harder. Therefore, in retrospective studies there is some danger in standardising for the number of cigarettes currently smoked or depth of inhalation. If one is able to standardise for these variables measured at an earlier time when current smokers of filter and plain cigarettes were both smoking the same cigarette, this would be a better procedure. There is evidence, however, that in the long run cigarette smokers who switch to reduced $\mathrm{T} / \mathrm{N}$ increase the number smoked a day to at most a very minor extent. ${ }^{22}$

(5) Finally, health at time of switching should be taken into account. If smokers switch to filter cigarettes because they are suffering from symptoms of smoking-associated diseases, a biased picture will be obtained. On the other hand, smokers who smoke cigarettes with reduced $\mathrm{T} / \mathrm{N}$ may quit smoking at a higher rate than those who smoke higher $T / N$ cigarettes. ${ }^{23}$
Results

OVERALL MORTALITY

In Table 4 the results from the three prospective studies are summarised. Hammond ${ }^{9}$ presented data for two periods of time for each sex. Since the trend of the ratios for each of the four groups was consistent, he combined all groups to show that smokers of 'medium $\mathrm{T} / \mathrm{N}$ ' cigarettes had $9 \%$ lower mortality rates and smokers of 'low $\mathrm{T} / \mathrm{N}$ ' cigarettes had $16 \%$ lower mortality rates than had smokers of 'high $T / N$ ' cigarettes. The differences between high and low $T / N$ groups, and high and medium $\mathrm{T} / \mathrm{N}$ groups, shown in Table 4 (except for one comparison) are highly statistically significant. In the migrants study, both men and women smokers of filter cigarettes had lower mortality than smokers of plain cigarettes, but the differences were not statistically significant. When both sexes were combined, there was a $13 \%$ lower mortality $(p<0 \cdot 05)$. No difference between filter and plain cigarette smokers was seen in the Hawthorne study. ${ }^{15}$

\section{LUNG CANCER}

The earliest evidence that filter and plain cigarettes had different intensities of associations with lung cancer came from the Doll and Hill hospital study. ${ }^{24}$ Although only three cases and 15 controls reported ever having smoked filter cigarettes regularly, a significant filter : plain mortality ratio of $0 \cdot 18(95 \%$ confidence limits of $0.06-0.59$ ) was observed. The small group of people who used filter cigarettes may have been unusual in some other way-Doll and Hill pointed out that the small group who used filter cigarettes were predominantly light smokers but said there were insufficient data to standardise for this and thus there was a need for caution in interpretation.

Subsequent evidence is summarised in Table 5. In the retrospective studies, men smokers of filter cigarettes had a reduced risk of lung cancer compared with smokers of plain cigarettes and, in many cases, the reduction was statistically significant and substantial. In women, the differences were not statistically significant. In the American Cancer Society study, the mortality for low and medium T/N men smokers was less than for high T/N smokers, but the differences were not statistically significant. Differences among women were larger and three of the four comparisons were statistically significant. Overall, the results suggest that smokers of filter cigarettes may have lung cancer rates about $25 \%$ lower than smokers of plain cigarettes. The combined data from the American Cancer Society study shows low $\mathrm{T} / \mathrm{N}$ smokers with $26 \%$ lower lung cancer mortality than high $\mathrm{T} / \mathrm{N}$ smokers. 
The Dean study ${ }^{16}$ showed that lung cancer rates tended to be lower for those who had smoked filter cigarettes longer. Compared with men who were reported to smoke plain cigarettes in 1954, 1964, and 1969, those who smoked plain cigarettes in 1954 and 1964 but filter in 1969 had 42\% less risk; those who smoked plain in 1954 but filter in 1964 and 1969 had 57\% less risk; and those who always smoked filter had $61 \%$ less risk. Results for women were similar. This study also showed that having first standardised for age, standardising for other cofactors scarcely affected the filter : plain mortality ratio.

Kunze $^{8}$ computed scores for lung cancer cases and controls based on the product of the number of cigarettes smoked a day, number of years smoked, and $\mathrm{T} / \mathrm{N}$ level for each brand. He found that those with tar exposure scores of 5000 or more had nearly four times the relative risk of lung cancer of those with scores of less than 500 .

Auerbach's pathological study ${ }^{10}$ showed that the degree of pathological changes seen in subjects dying in 1955-60 who smoked 1-19 cigarettes a day was remarkably similar to that in subjects dying in 1970-77 who smoked $40+$ cigarettes a day. If the lesions studied by Auerbach (basal cell hyperplasia, absence of cilia, presence of atypical nuclei) have a direct relationship to lung cancer, one old cigarette would seem to be equivalent to perhaps three or four modern cigarettes.

OTHER CANCERS

Table 6 gives new data from the American Cancer Society's study on cancer of the buccal cavity and pharynx, oesophagus, larynx, bladder, and pancreas, for both periods combined, by sex. All of these sites of cancer have been associated with smoking to some degree. Lung cancer mortality ratios by sex for both periods combined are also shown in the Table. Except for lung cancer, the mortality ratios shown in Table 6 are based upon small numbers of adjusted deaths in each cell and only a few of the comparisons are statistically significant. However, for lung cancer and the other cancers, except cancer of the pancreas, smokers of low $\mathrm{T} / \mathrm{N}$ cigarettes had the lowest risk and smokers of medium $\mathrm{T} / \mathrm{N}$ cigarettes had an intermediate risk. Wynder ${ }^{14}$ also showed a substantially reduced risk of larynx cancer in smokers of filter cigarettes.

HEART DISEASE

Table 7 summarises data available on coronary heart disease. Overall, there is an impression of a small decrease for smokers of filter or low $\mathrm{T} / \mathrm{N}$ cigarettes, although the trend is not completely consistent in each time period and sex group in the American Cancer Society study. The difference in risk in the
Dean study ${ }^{20}$ is more marked when long-term filter smokers are compared with long-term plain smokers. Filter : plain mortality ratios in the Dean study were also calculated for separate age groups. The ratios found (35-44-year-olds $=0.34 ; 45-54=0.67$; $55-64=0 \cdot 94)$ are consistent with there being a larger difference in the age groups where the association with smoking is strongest.

\section{OTHER DISEASES}

Table 8 shows new data from the American Cancer Society for several other diseases associated with smoking, for both periods combined, by sex. Coronary heart disease mortality ratios by sex for both periods combined are also shown in this Table.

Coronary heart disease showed slightly lower mortality ratios for medium $\mathrm{T} / \mathrm{N}$ smokers in both men and women. All the differences shown for coronary heart disease were statistically significant. The difference in male stroke mortality between low and high $\mathrm{T} / \mathrm{N}$ smokers was also statistically significant; the mortality ratio $(0.71)$ was similar to the filter : plain mortality ratio seen in the migrants study $(0.66 ; p<0.05)$ and in the Dean study $(0.68$; NS). There were no differences in stroke mortality in women. The mortality ratios for aortic aneurysm were based upon much lower numbers of adjusted deaths and showed no consistent trend for more favourable mortality in medium and low $T / N$ smokers. Koch ${ }^{7}$ and $W_{y n d e r}{ }^{13}$ have presented preliminary data suggesting a lower risk of peripheral arterial disease in filter compared with plain cigarette smokers.

The reduced risk for cirrhosis of the liver is large and consistent in both sexes. The differences are statistically significant in three of the four comparisons.

The relative mortality for emphysema was consistently lower in low and medium $\mathrm{T} / \mathrm{N}$ smokers. For low $\mathrm{T} / \mathrm{N}$ smokers, it was 0.78 in men and 0.59 in women. Dean ${ }^{16}$ showed a relative risk of 0.66 for chronic bronchitis for men and $\mathbf{0 . 4 2}$ for women in filter compared with plain cigarette smokers, reductions which were statistically significant ( $p<0.05$ and $p<0.01$ respectively).

There were only a small number of adjusted deaths from gastrointestinal ulcer with no consistent pattern.

\section{Conclusions}

Any study comparing risks in smokers of differing cigarette types is open to the problems of interpretation mentioned earlier. Marked differences between the studies considered, in type of study carried out, in sample size, in the statistical analysis, in reference period time of the study, in the 
population, and in the type of comparisons, make it remarkable that any picture should appear at all. However, our impression is that a reasonably clear picture has emerged. This is that smokers of filter (or low $T / N$ ) cigarettes have a lower mortality than smokers of plain (or high $\mathrm{T} / \mathrm{N}$ ) cigarettes for those diseases most strongly associated with smoking and a slightly reduced mortality for those diseases less associated with smoking.

These reductions in mortality have been seen in those who have smoked the more modern types of cigarettes for only a relatively small part of their smoking lives. The fact that those who have smoked them for a longer time show even greater reductions in mortality suggests that the overall picture will improve even more in years to come, especially since further reductions in the average tar level of cigarettes have occurred. We have no evidence on the risk run by the smokers smoking brands in the 8-10 $\mathrm{mg}$ range, and the research which is continuing on risk by type of cigarette smoked is of vital importance. One of these is Wynder's continuing study in 13 hospitals in the USA. Another is Alderson's English hospital study of lung cancer, chronic bronchitis, ischaemic heart disease, and stroke. The third is Wald's study of people attending the BUPA clinic in London for routine health examinations. Other groups may also be collecting data on the subject.

We thank G. A. Rose for permission to quote unpublished findings from the migrants study and also R. Peto, N. Wald, and M. R. Alderson for their helpful comments on earlier drafts of this paper.

Reprints from Mr. P. N. Lee, 25 Cedar Road, Sutton, Surrey SM2 5DG.

\section{References}

${ }^{1}$ Doll R, Hill AB. Smoking and carcinoma of the lung. $\mathrm{Br}$ Med J 1950; ii: 739-48.

${ }^{2}$ Royal College of Physicians. Smoking or Health. The Third Report from the Royal College of Physicians of London. London: Pitman Medical, 1977.

${ }^{3}$ Surgeon General. Smoking and Health. A Report of the Surgeon General. Washington DC: Department of Health, Education and Welfare, 1979.

${ }^{4}$ Todd GF. Changes in smoking patterns in the UK. TRC Occasional Paper No. 1. London: Tobacco Research Council, 1975.

${ }^{5}$ Weber KH. Recent changes in tobacco products and their acceptance by the consumer. Proceedings of the Sixth International Tobacco Scientific Congress, Coresta, Tokyo, 1976: 15-30.

${ }^{6}$ Wald NJ, Howard S, Evans J. Smoking tables for carbon monoxide. $\mathrm{Br}$ Med J 1976; i: 434-5.

${ }^{7}$ Koch A. Smoking and peripheral arterial disease. Proceedings of the Third World Conference on Smoking and Health, New York City 2-5 June 1975; 1: 281-3.

${ }^{8}$ Kunze M, Vutuc C. Threshold of tar exposure: Analysis of smoking history of male lung cancer cases and controls.
In: Gori G, Bock F, ed. Banbury Report No. 3: A Safe Cigarette? New York: Cold Spring Harbor Laboratory, 1980: 29-36.

${ }^{9}$ Hammond EC, Garfinkel L. Seidman H, Lew EA. 'Tar' and nicotine content of cigarette smoke in relation to death rates. Environ Res 1976; 12: 263-74.

${ }^{10}$ Auerbach O, Hammond EC, Garfinkel L. Changes in bronchial epithelium in relation to cigarette smoking 1955-1960 vs. 1970-1977. N Engl J Med 1979; 300: 381-6.

${ }^{11}$ Bross IDJ, Gibson R. Risk of lung cancer in smokers who switch to filter cigarettes. Am J Public Health 1968; 58: 1396-1403.

${ }^{12}$ Wynder EL, Mabuchi K, Beattie EJ. The epidemiology of lung cancer. Recent trends. JAMA 1970; 213: 2221-8.

${ }^{13}$ Wynder EL, Mushinski M, Stellman S. The epidemiology of the less harmful cigarette. Proceedings of the Third World Conference on Smoking and Health, New York City 2-5 June 1975; 1: 1-12.

${ }^{14}$ Wynder EL, Stellman SD. The impact of long-term filter cigarette usage in lung and larynx cancer risk: A case-control study. J Natl Cancer Inst 1979; 62: 471-7.

${ }^{15}$ Hawthorne VM, Fry JS. Smoking and health; cardiorespiratory disease, mortality, and smoking behaviour in West Central Scotland. $J$ Epidemiol Community Health 1978; 32: 260-6.

${ }^{16}$ Dean G, Lee PN, Todd GF, Wicken AJ. Report on a second retrospective mortality study in North-East England. Part I: Factors related to mortality from lung cancer, bronchitis, heart disease and stroke in Cleveland County, with particular emphasis on the relative risks associated with smoking filter and plain cigarettes. TRC Research Paper No. 14, Part I. London: Tobacco Research Council, 1977.

${ }^{17}$ Reid DD. Studies of disease among migrants and native populations in Great Britain, Norway, and the L'nited States. 1. Background and Design. National Cancer Institute Monograph No. 19. Bethesda, Maryland: NIH, 1966: 287-99.

${ }^{18} \mathrm{Kahn}$ HA. The Dorn study of smoking and mortality among US veterans: Report on eight and one-halfyears of observation. National Cancer Institute Monograph No. 19. Bethesda, Maryland: NIH, 1966: 1-125.

${ }^{19}$ Hammond EC. Smoking in relation to the death rates of one million men and women. National Cancer Institute Monograph No. 19. Bethesda, Maryland: NIH, 1966: 127-204.

${ }^{20}$ Dean G, Lee PN, Todd GF, Wicken AJ. Report on $a$ second retrospective mortality study in North-East England. Part II: Changes in lung cancer and bronchitis mortality and other relevant factors occurring in areas of North-East England 1963-72. TRC Research Paper No. 14. Part II. London: Tobacco Research Council, 1978.

${ }^{21}$ Dean G, Lee PN, Todd GF, Wicken AJ. Factors related to respiratory and cardiovascular symptoms in the United Kingdom (with supplementary tabulations). $J$. Epidemiol Community Health 1978; 32: 86-96.

${ }^{22}$ Garfinkel L. Changes in number of cigarettes smoked compared to changes in tar and nicotine content over a 13-year period. In: Gori G, Bock F, ed. Banbury Report No. 3: A Safe Cigarette? New York: Cold Spring Harbor Laboratory, 1980: 13-18.

${ }^{23} \mathrm{Hammond} \mathrm{EC}$. The long-term benefits of reducing tar and nicotine in cigarettes. In: Gori G, Bock F, ed. Banbury Report No. 3: A Safe Cigarette? New York: Cold Spring Harbor Laboratory, 1980: 13-18.

${ }^{24}$ Doll R, Hill AB. A study of the aetiology of carcinoma of the lung. Br Med J 1952; ii: 1271-86.

${ }^{25}$ Lee PN, ed. Statistics of smoking in the United Kingdom. TRC Research Paper, No. 1, 7th edn. London: Tobacco Research Council, 1976. 